\title{
Molecular and morphological characterization of heterorhabditid entomopathogenic nematodes from the tropical rainforest in Brazil
}

\author{
Claudia Dolinski/ ${ }^{+}$, Fernando L Kamitani ${ }^{1}$, Inês R Machado, Carlos E Winter ${ }^{1}$ \\ LEF/CCTA, Universidade Estadual do Norte Fluminense Darcy Ribeiro, Av. Alberto Lamego 2000, 28015-620 Campos dos Goytacazes, \\ Rio de Janeiro, Brasil 'Departamento de Parasitologia/ICB2, Universidade São Paulo, São Paulo, Brasil
}

\begin{abstract}
Despite massive losses of primary forest, the Amazonian rainforest remains an extremely rich source of biodiversity. In recent years, entomopathogenic nematodes (EPNS) have been isolated from soil in various parts of the world and used successfully as biological control agents against numerous insect pests. Therefore, a sampling in the rainforest of Monte Negro, Rondônia, Brazil was conducted with the aim of discovering new strains and/or species of EPNs for future development as biological control agents. From 156 soil samples taken at nine collecting sites, 19 isolates were obtained, all of them belonging to the genus Heterorhabditis. Four strains were subjected to detailed morphological and molecular evaluation. Based on morphometrics and internal transcribed spacer (ITS) sequence data, the strains LPP1, LPP2 and LPP4 were identified as Heterorhabditis indica, whereas LPP7 was considered Heterorhabditis baujardi. Comparative analysis of the ITS1 sequence of $\mathrm{H}$. indica and $\mathrm{H}$. baujardi isolates showed a polymorphic site for the restriction enzyme Tth 111 that could be used to distinguish the two species. Consequently, strains LPP1, LPP2, LPP3, LPP4, and LPP9 were identified as $\mathrm{H}$. indica, whereas LPP5, LPP7, LPP8 and LPP10 were identified as $\mathrm{H}$. baujardi.
\end{abstract}

Key words: Heterorhabdtidae - taxonomy - Nematoda - phylogeny - Brazil

Entomopathogenic nematodes (EPNs) of the families Heterorhabditidae and Steinernematidae are obligate parasites of insects and are frequently used as biological control agents of economically important insect pests. The two major genera are Heterorhabditis Poinar, and Steinernema Travassos, with 43 and ten species, respectively (Adams et al. 2006). Surveys for EPNs conducted in various parts of the world reveal that these genera have global distributions. To date, the only places where these nematodes have not been found is Antarctica (Hominick 2002). During the 1990 s, most published surveys had insufficient data to test for correlations between habitat variables and EPN distributions (Hominick et al. 1996). However, as more surveys occurred, with larger sample sizes and more accurate identifications, some habitat associations were proposed. Heterorhabditids were thought to be associated with sandy coastal soils but more and more Heterorhabditids have been reported away from coast lines, and these include Heterorhabditids indica Poinar, Karunakar and David (Poinar et al. 1992, Phan et al. 2003), Heterorhabditids mexicana Nguyen, Shapiro-Ilan, Stuart, McCoy, James and Adams (Nguyen et al. 2004), and Heterorhabditids bacteriophora Poinar (Stock et al. 1996). Thus, it is likely that EPN habitat preference reflects the prevalence of suitable hosts (Hominick 2002) and species-specific

Financial support: FAPESP, PRONEX, CNPq

+ Corresponding author: claudia.dolinski@censanet.com.br

Received 20 August 2007

Accepted 18 February 2008 environmental adaptations (Smits \& Ehlers 1991), with each species being physiologically and behaviorally adapted for survival in a range of different habitats. In the Azores, H. bacteriophora displayed no habitat preference and was recorded from cropland, woodland, pasture, orchard and native vegetation (Rosa et al. 2000). Similarly, in New Jersey, $H$. bacteriophora was found broadly distributed in turf and weedy habitats (Stuart \& Gaugler 1994). Recent surveys in tropical forests indicate that the most common nematodes in this habitat are H. indica and Heterorhabditids baujardi Phan, Subbotin, Nguyen and Moens (Mason et al. 1996, Josephrajkumar \& Sivakumar 1997, Phan et al. 2003).

The main characteristics that should be used for Heterorhabditis species distinctions are a matter of debate. The nematodes of this genus lack morphological variation and some valid characters are hard to see or require careful observation (e.g., spicules). In general, it appears that various morphological features of males and infective juveniles (e.g., number and arrangement of the genital papillae, plus spicule and gubernaculum shape) should be taken into consideration together with morphometric characters (Stock \& Kaya 1996, Phan et al. 2003, Nguyen et al. 2004). In addition, molecular data (e.g., internal transcribed spacerl(ITS1) sequence) should also be incorporated into descriptions (Hominick et al. 1997, Adams et al. 2006).

Native species of entomopathogenic nematodes that are adapted to local environmental and climatic conditions are especially good candidates for use as biological control agents. The objective of the present study was to isolate EPNs from the Southwestern Amazonian rain forest of Monte Negro, Rondônia, Brazil, for future biological control programs and to identify them based on morphometrics and ITS1 sequences. 


\section{MATERIALS AND METHODS}

Sampling - Soil samples were collected from nine sampling sites within the Southwestern Amazonian rain forest of Monte Negro, Rondônia, Brazil (10¹7'17.43”'S, $63^{\circ} 19^{\prime} 17.59^{\prime \prime} \mathrm{W}$ ) (Fig. 1). The collecting points were chosen randomly, but always close to trees from the primary forest (e.g., Tabebuia alba, Aspidosperma cylindrocarpum, Ouratea semisserrata, and Chorisia speciosa). The samples were taken from 5 to $10 \mathrm{~cm}$ deep and within 100 to $500 \mathrm{~m}$ of fresh water. EPNs were isolated from soil by the insect-baiting technique using Galleria mellonella L. (Lepidoptera: Pyralidae) (Bedding \& Akhurst 1975). All soil samples were kept for granulometric analysis. Larvae showing symptoms of EPN infection were kept in Petri dishes with filter paper on the bottom for two or three days. Then, they were washed in sodium hypoclorite $1 \%$ for $30 \mathrm{~s}$ and placed on modified White traps for infective juveniles (IJs) emergence. Different isolates were multiplied in the laboratory on last instar G. mellonella larvae and stored at $16^{\circ} \mathrm{C}$ (White 1927, Dutky et al. 1964). Each isolate was identified by the letters LPP (Laboratório de Proteção de Plantas, the former name of the present Laboratório de Fitopatologia e Entomologia) and a serial number.

Morphological observations - For morphological studies, third-stage IJs were obtained within seven days of emergence from insect cadavers (Nguyen \& Smart Jr. 1995). Other nematode stages were obtained by infecting ten G. mellonella larvae with $500 \mathrm{IJs} / \mathrm{ml}$ in Petri dishes $(90 \times 15 \mathrm{~cm})$ lined with filter paper. First generation hermaphrodites and second generation females and males were dissected from the cadavers 6-7 and 8-9 days after infection, respectively. All observations and measurements were performed within one week of harvest.

Slides of fresh nematodes were mounted in Ringer's solution and sealed with paraffin. At least 15 males, 5 females, 5 hermaphrodites and 30 IJs of each isolate were observed, drawn and measured. Measurements were made using a drawing camera (camera lucida) (Axioplan Axiophoto) attached to a Zeiss (MC100 SPOT) light microscope.

Molecular characterization - IJs were harvested from distilled water in modified white traps and processed while fresh. After being washed three times with distilled water, nematodes were concentrated by centrifugation $(1,000 \mathrm{~g}$ for $1 \mathrm{~min})$. Then genomic DNA was extracted using Wizard ${ }^{\circledR}$ SV Genomic DNA Purification System (Promega Corp, Madison, WI) following the manufacturer's instructions. The genomic DNA obtained was then quantified by spectrophotometry. Protocols for genomic DNA extraction without the use of kits can be found in Adams et al. (1998) and Stock et al. (2001).

Polymerase chain reaction (PCR) was used to amplify the rDNA comprising both ITS one and two, covering the 5.8S rDNA gene [ITS1+5.8S+ITS2] $(1,094 \mathrm{bp}$ in Caenorhabditis elegans). The forward primer (SSU18PF, GTGAACCTGCRGMWGGATCA) was modified from oligonucleotide NC5 (Newton et al. 1998) over the sequences of large subunit ribosomal RNA (LSU rR-
NAs) from several nematode species used by Blaxter et al. (1998) and corresponds to positions 2671..2690 of the rRNA genes of C. elegans (GenBank Acc. Nr. X03680). The reverse primer (LSU-NC2, TTAGTTTCTTTTCCTCCGCT) is a universal primer for the LSU rRNA genes of nematodes (Blaxter et al. 1998, see Wimmer 2007) that corresponds to positions $3745 . .3764$ of the rRNA genes of C. elegans (GenBank Acc. Nr. X03680). PCR conditions such as annealing temperature and $\mathrm{MgCl}_{2}$ or deoxynucleoside triphosphates (dNTP's) concentrations were empirically optimized. Platinum Taq DNA Polimerase (Invitrogen, Carlsbad, CA) was used for PCR amplifications. Buffer, $\mathrm{MgCl}_{2}$ and dNTP's solutions were supplied by the manufacturer.

The standard reaction included up to $200 \mathrm{ng}$ of genomic DNA, $0.1 \mu \mathrm{M}$ of each primer, $10 \mathrm{mM}$ of dNTP's solution, $5 \mathrm{mM}$ of $\mathrm{MgCl}_{2}$ and Buffer $1 \mathrm{X}(20 \mathrm{mM}$ Tris- $\mathrm{HCl}$ $\mathrm{pH}$ 8.4, $50 \mathrm{mM} \mathrm{KCl}$ and no $\mathrm{MgCl}_{2}$ added) in a volume of $25 \mu$ l. Standard cycling parameters included denaturation at $94^{\circ} \mathrm{C}$ for $2 \mathrm{~min}$, followed by 30 cycles of $94^{\circ} \mathrm{C}$ for $45 \mathrm{~s}, 55^{\circ} \mathrm{C}$ for $30 \mathrm{~s}$ and $72^{\circ} \mathrm{C}$ for $90 \mathrm{~s}$, followed by a post-amplification extension at $72^{\circ} \mathrm{C}$ for $5 \mathrm{~min}$.

DNA fragment presence and yield was measured by agarose gel electrophoresis ( $1 \%$ in $1 \mathrm{X}$ TAE buffer). PCR products were prepared for cloning or direct sequencing using Microcon ${ }^{\circledR}$ PCR microcolumn (Milipore, Bedford, Massachusetts) following manufacturer's instructions. This step aimed to clear the PCR product from excess salts and primers. PCR fragments were always cloned before final sequencing, but before cloning they were test sequenced to ensure identity. The fragments from all lineages were subcloned into plasmid TOPO2.1 ${ }^{\circledR}$ (Invitrogen, Carlsbad, California) in order to avoid the loss of unique isolate fragments and to increase DNA quantity for sequencing.

Sequencing reactions were performed using Big Dye ${ }^{\circledR}$ (Perkin Elmer, Norwalk, Connecticut) terminator cycle sequencing chemistry, and reaction products were separated and detected using an ABI 3100 automatic sequencer.

Sequence analysis - No variation was observed among different clones of the same isolate. Perhaps if we increased the number of observed clones then those

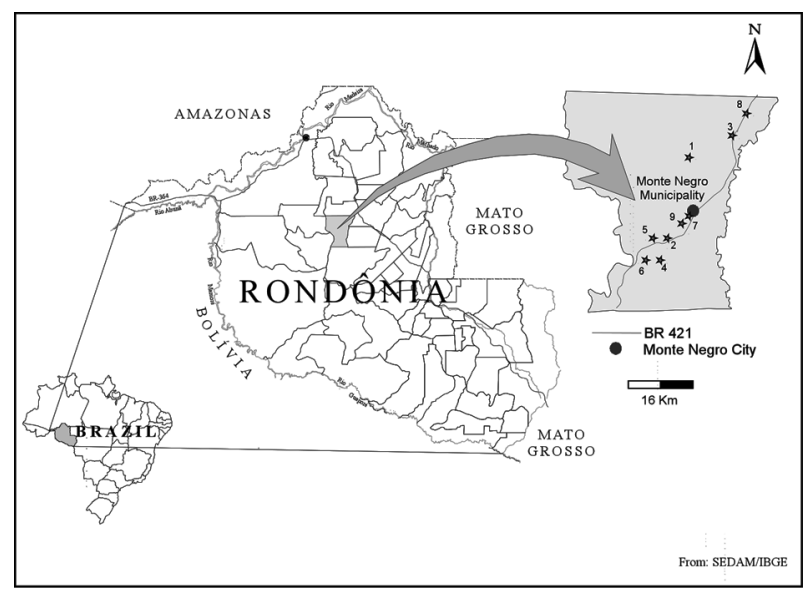

Fig. 1: map showing collecting points in Monte Negro municipality, Rondônia, Brazil. 
variations would be visible. The "indica group" shows almost no variation among different isolates from around the world (see results). Sequence alignments were made in Clustal X (v. 1.81, Thompson et al. 1997) using the default parameters (gap opening 15.00, gap extension 6.66). Alignment was checked visually for any inconsistency using the EyeBall Sequence Editor (ESEE v. 3.2s). Using the 18S-5.8S-28S rRNA genes of C. elegans (Genbank acc. nr. X03680) as guide sequences, the ITS1 and ITS2 boundaries were determined and excised from the original files for creation of the alignment files.

PAUP (ver 4.0b10) was used for phylogenetic analysis of aligned sequences. Maximum likelihood (ML) and maximum parsimony (MP) trees of ITS one sequences were constructed using the substitution model GTR+I selected by hLRT with Modeltest 3.7. (Posada \& Crandall 1998). ML for ITS1+ITS2 sequences used the substitution model GTR $+\mathrm{G}$ also selected with Modeltest 3.7. Bootstrap values were obtained by an heuristic search over $100 \mathrm{MP}$ or $1,000 \mathrm{ML}$ replicates.

Sequences used in this work (with their Accession Numbers in GenBank): Heterorhabdits amazonensis (DQ665222), H. bacteriophora (AF029708), H. baujardi (AF548768), H. mexicana (AY321478), Heterorhabdits marelata (AY321479), Heterorhabdits megidis (AY321480), Heterorhabdits downesi (AY321482), H. indica (AY321483), Heterorhabdits zealandica (DQ100268), Heterorhabdits brevicaudis (DQ177908), LPP1 (EU363042), LPP2 (EU363040), LPP3 (EU363041), and LPP7 (EU363039).

\section{RESULTS AND DISCUSSION}

From 156 soil samples taken at nine collecting points in the rainforest of Monte Negro, Rondônia, we obtained 19 Heterorhabditis isolates $(12,18 \%)$. Most of the positive soil samples were classified as sandy clay loam or sandy loam (Table I).

Based on Stock and Kaya (1996) and Hominick et al. (1997), the morphological aspects of males and IJs give the majority of taxonomic characters necessary to identify Heterorhabditis species. Specifically, body (L) and tail (T) length in IJs, plus body and testis reflexion in males are used to differentiate species. However, Phan et al. (2003) suggest that characters such as L length in IJs, and spicule and gubernaculum length and shape in males are the ones that should be given most consideration. Nguyen and Smart Jr (1995) indicated that characters such as L and T length of IJs, and distance from the anterior end to the excretory pore (EP) are good characters, but that they vary with time of harvest. The E\% (EP/T.100) is the least variable.

Another criterion of identification recently being used is the morphometrics of the bursa. Nguyen et al. (2004) stated that the number of bursal papillae is generally constant amongst Heterorhabditis species. However, analyzing strains LPP1, LPP2, LPP4 and LPP7 and different species descriptions, we found great variability in papillae number and shape within species (Table II, Fig. 2). Therefore, this character was not used for identification (Fitch 2000).

The species $H$. indica, $H$. baujardi, $H$. mexicana, Heterorhabdtis floridensis Nguyen, Gozel, Koppenhofer and Adams, and H. amazonensis Andaló, Nguyen and Moino Jr are considered very closely related based on molecular and morphological data and are part of the so called "indica-group" (Nguyen et al. 2004, Andaló et al. 2006). Our observations of various characters of IJs of these species indicate that all values overlap and that the averages are frequently very similar (Table III). The only characters that were different under strict statistical analysis were the indexes $\mathrm{E} \%$, c and $\mathrm{f}$, perhaps because we used the value of $T$ length without sheath to obtain the indexes. Data on T length without sheath could not be found in $H$. baujardi's or $H$. indica's original descriptions for comparison. Therefore, we could not differentiate our strains from the above species based on IJ characters.

In terms of males, we encountered a similar situation to that of the IJs except for the characters EP and D\%. Based on EP, LPP2 (110-121) and LPP4 (110-130) could be differentiated from LPP7 (87-107) and H. baujardi (71107). Based on this criterion, LPP7 could also be differentiated from H. indica (109-138) and H. mexicana (108-145). Looking at the D\%, only LPP7 could be differentiated from $H$. mexicana and $H$. floridensis. Strain LPP7 was not compared to $H$. baujardi by this index because it was not present in the original description. Strain LPP1
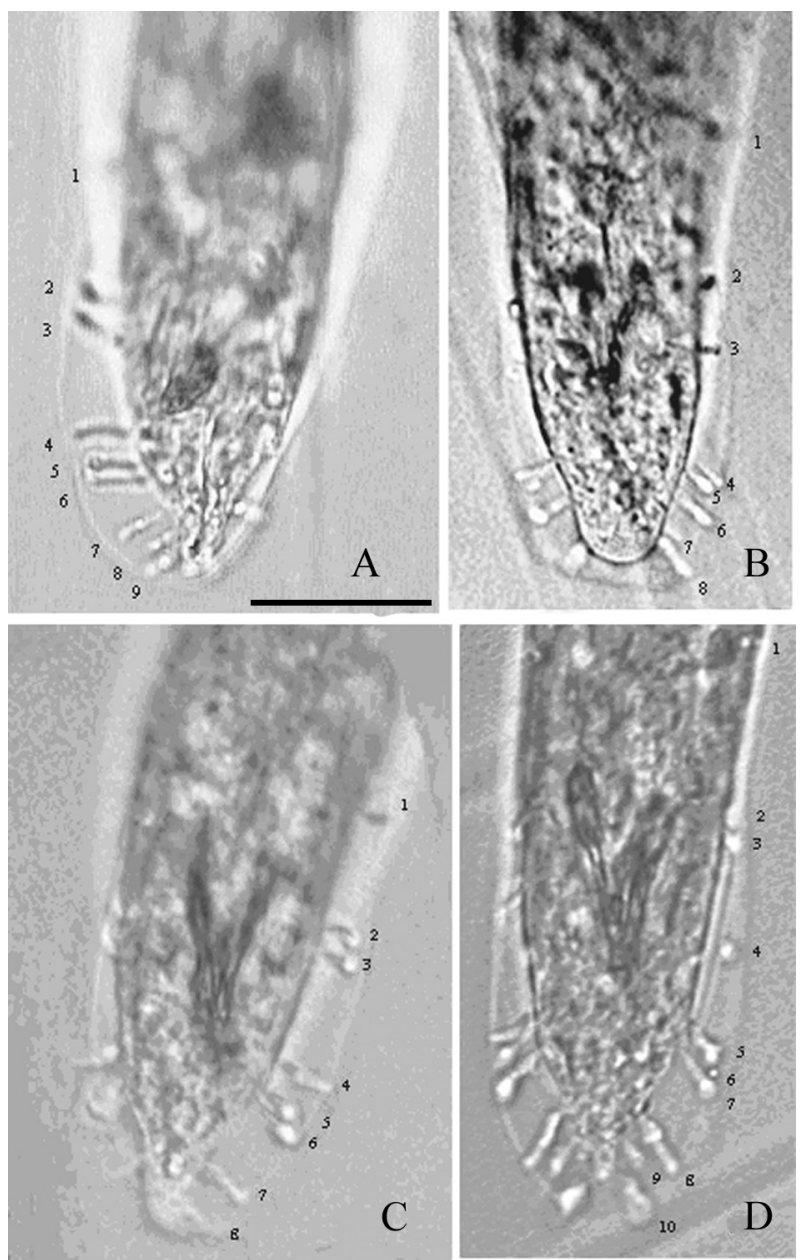

Fig. 2: light microscope photograph of male posterior region showing bursal papillae. A: Heterorhabditis indica LPP1; B: H. indica LPP2; C: H. indica LPP4; D: Heterorhabditis baujardi LPP7. Scale bar: $30 \mu$. 
TABLE I

List of isolates obtained from nine different collecting points in Monte Negro municipality, Rondônia, Brazil, granolometric analysis and classification of their associated soil (\%)

\begin{tabular}{|c|c|c|c|c|c|}
\hline Isolate number & Total sand & Silt & Clay & Texture classification & Collecting point $^{a}$ \\
\hline$L P P 1$ & 63 & 17 & 20 & Sandy clay loam & 7 \\
\hline$L P P 2$ & 64 & 14 & 22 & Sandy clay loam & 5 \\
\hline$L P P 3$ & 62 & 15 & 23 & Sandy clay loam & 7 \\
\hline LPP4 & 83 & 3 & 14 & Sandy loam & 9 \\
\hline$L P P 5$ & 73 & 9 & 18 & Sandy loam & 9 \\
\hline$L P P 6$ & 82 & 3 & 15 & Sandy loam & 7 \\
\hline$L P P 7$ & 83 & 4 & 13 & Loamy sand & 7 \\
\hline$L P P 8$ & 84 & 4 & 12 & Loamy sand & 7 \\
\hline$L P P 9$ & 53 & 19 & 28 & Sandy clay loam & 9 \\
\hline LPP10 & 68 & 15 & 17 & Sandy loam & 7 \\
\hline LPP11 & 65 & 13 & 22 & Sandy clay loam & 6 \\
\hline LPP12 & 62 & 17 & 21 & Sandy clay loam & 4 \\
\hline$L P P 13$ & 80 & 17 & 3 & Loamy sand & 4 \\
\hline LPP14 & 64 & 8 & 28 & Sandy clay loam & 3 \\
\hline LPP15 & 74 & 6 & 20 & Sandy clay loam & 8 \\
\hline LPP16 & 41 & 12 & 47 & Clay & 2 \\
\hline LPP17 & 87 & 3 & 10 & Loamy sand & 8 \\
\hline LPP18 & 63 & 13 & 24 & Sandy clay loam & 3 \\
\hline LPP19 & 63 & 20 & 17 & Sandy loam & 3 \\
\hline
\end{tabular}

$a$ : see Fig. 1 for localization of collecting points.

TABLE II

Arrangement of bursal papillae in different Heterorhabditis species

\begin{tabular}{|c|c|c|c|}
\hline Species & Number of papillae & Principal formula & Grouping references \\
\hline H. amazonensis & 8 & $1,2,3,2$ & Andaló et al. 2006 \\
\hline H. bacteriophora & 9 & $1,2,3,3$ (9th pair variable) & Poinar 1976 \\
\hline H. baujardi & 8 or 9 & $1,2,3,2$ or $1,2,3,3$ & Phan et al. 2003 \\
\hline H. brevicaudis & 9 & $1,2,3,3$ & Liu 1994 \\
\hline H. floridensis & 8 or 9 & $1,2,3,2$ or $1,2,3,3$ & Nguyen et al. 2006 \\
\hline H. hawaiiensis (syn. H. indica) & 9 & $1,2,3,3$ (7th and 8th pairs shorter) & Gardner et al. 1994 \\
\hline H. indica & 8 or 9 & $1,2,3,2$ & Poinar et al. 1992 \\
\hline H. marelatus & 9 & $1,2,3,3$ (8th pair shorter) & Liu and Berry 1996 \\
\hline H. megidis & 9 & $1,2,3,3$ & Poinar et al. 1987 \\
\hline H. mexicana & 8 & $1,2,3,2$ & Nguyen et al. 2004 \\
\hline H. taysearae & 9 & $1,2,3,3$ & Shamseldean et al. 1996 \\
\hline H. zealandica & 9 & $1,2,3,3$ (8th pair shorter) & Poinar 1990 \\
\hline H. indica LPP1 & 8 or 9 & $1,2,3,2$ or $1,2,3,3$ & Present study \\
\hline H. indica LPP2 & 8 & $1,2,3,2$ & Present study \\
\hline H. indica LPP4 & 8 & $1,2,3,2$ & Present study \\
\hline H. baujardi LPP7 & 9 or 10 & $1,2,3,3$ or $1,2,1,3,3$ & Present study \\
\hline
\end{tabular}

could not be differentiated from described species by any means (Table IV). Although $\mathrm{D} \%$ is a valuable character due to its low variability, it was not sufficient to resolve the identification of all Brazilian strains (Nguyen \& Smart Jr 1995).

Gubernaculum shape seemed the most constant morphological character among all Heterorhabditis species studied, and was a good candidate for identification purposes. More than 20 males from each strain were observed under light microscope and we noticed great flexibility in the gubernaculum of some strains. This flexibility was shown when the spicule was eject- ed, and the gubernaculum tip presented a slight curve upwards (Figs 3, 4). Strain LPP1 presented a straight gubernaculum, being flexible in $60 \%$ of the specimens observed with an ejected spicule. Similar to strain LPP1, LPP2 also presented a straight and flexible gubernaculum ( $80 \%$ of the specimens). Strain LPP4 presented a straight gubernaculum but no specimens were observed with an ejected spicule. Eighty percent of the specimens from strain LPP7 presented the upper part of the gubernaculum curved and, even when the spicule was ejected, $100 \%$ of the specimens did not have it curved upwards (i.e., it was not flexible) (Figs 3, 4). 
The morphology of the gubernaculum was originally the most important criterion used to differentiate $H$. baujardi from $H$. indica. The original description of $H$. baujardi shows the upper part of the gubernaculum curved at the tip, with or without an ejected spicule, as shown in LPP7 (Poinar et al. 1992, Phan et al. 2003).

ITS analysis - PCR fragments obtained from LPP1, LPP2, LPP3, and LPP7 were sequenced and compared to other described species (Fig. 5). A preliminary analysis showed that LPP1, LPP2 and LPP3 ITS1 sequences were almost indistinguishable, with only five variable positions (Fig. 5). Their ITS1 sequence is almost identical to that of $H$. indica, which suggests that they all belong to the same species. The ITS1 sequence of LPP7 showed high similarity to $H$. baujardi.

A partial ML phylogenetic tree was constructed using ITS1+2 sequences from members of the "indica group" as described by Andaló et al. (2006) (Fig. 6). Using the ITS2 sequence together with the ITS1 avoided the polytomy of LPP1, LPP2, LPP3 and $H$. indica, and allowed us to include $H$. amazonensis sequences in the tree. This tree shows that LPP7 and H. amazonensis belong to the same clade and we can clearly distinguish two sub-groups of isolates: those (LPP1, LPP2 and LPP3) that group with $H$. indica, and LPP7 that groups with $H$. baujardi/H. amazonensis.
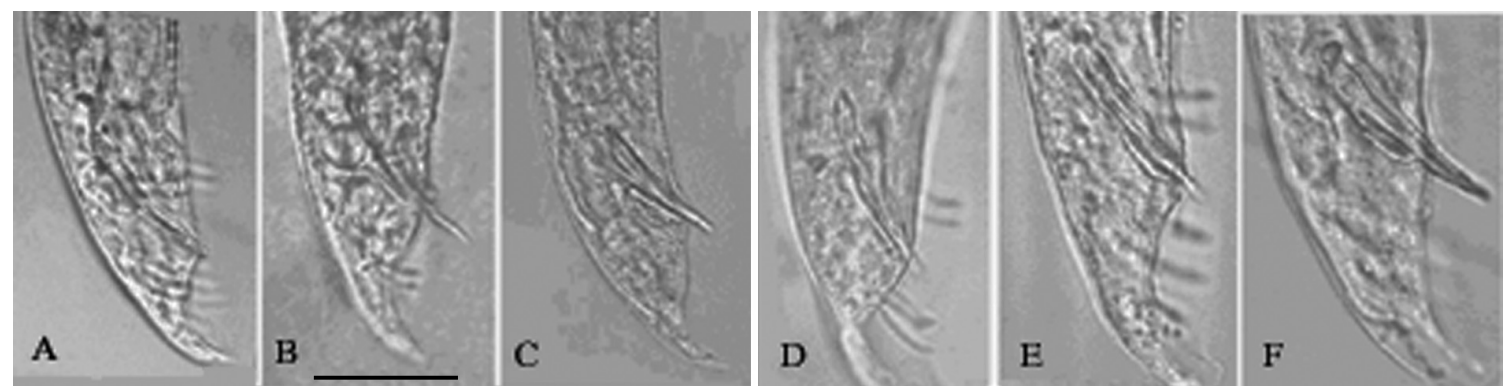

Fig. 3: light microscope photograph of male posterior region showing spicules and gubernaculum. A-C: Heterorhabditis indica LPP1; D-E: H. indica LPP2. Scale bar: $30 \mu$.
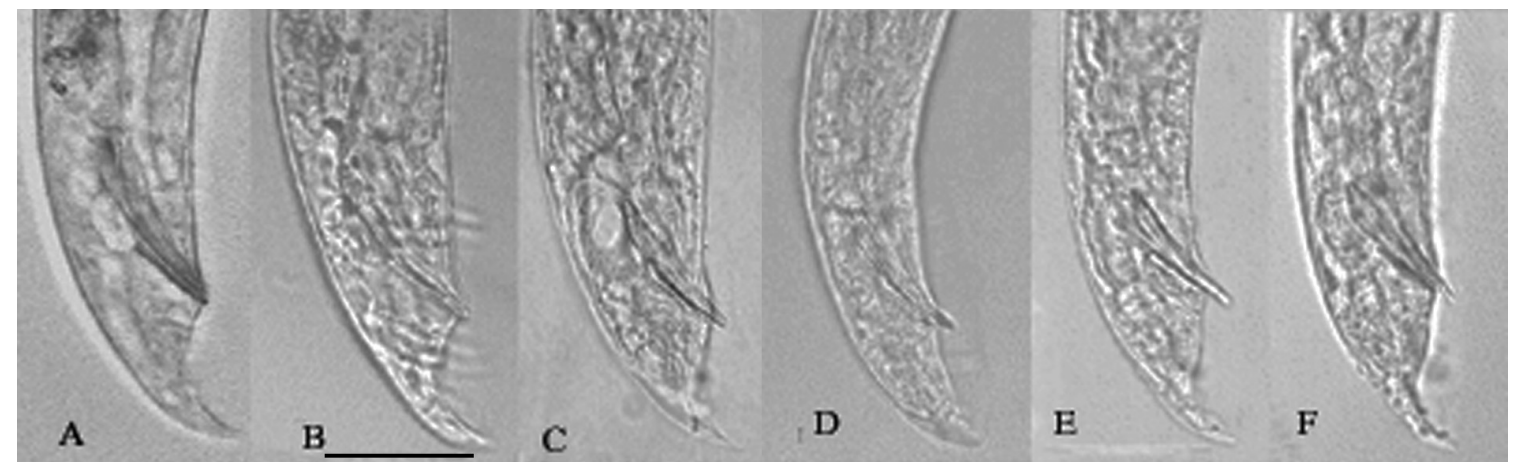

Fig. 4: light microscope photograph of male posterior region showing spicules and gubernaculum. A-B: Heterorhabditis indica LPP4; C-E: Heterorhabditis baujardi LPP7. Scale bar: $30 \mu$.

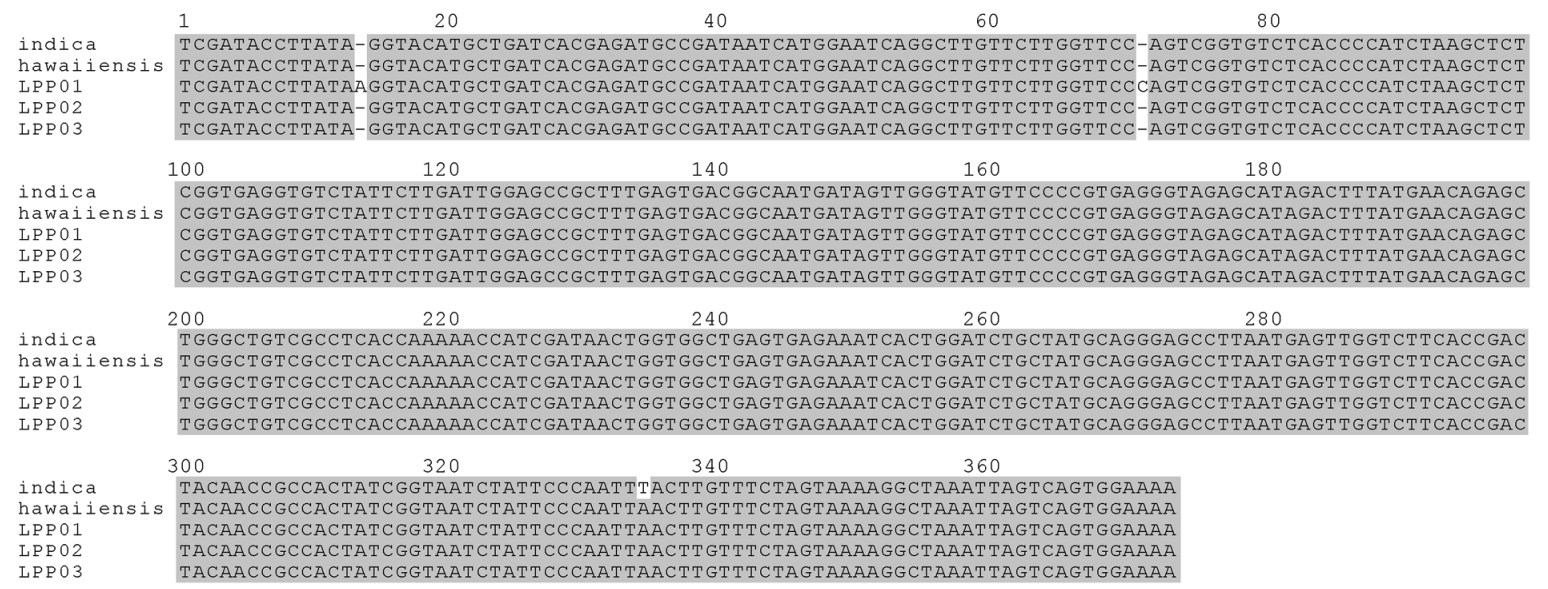

Fig. 5: alignment of ITS1 sequences from Heterorhabditis species LPP1, LPP2, LPP3, Heterorhabditis hawaiiensis and Heterorhabditis indica. Identical positions are shadowed. 


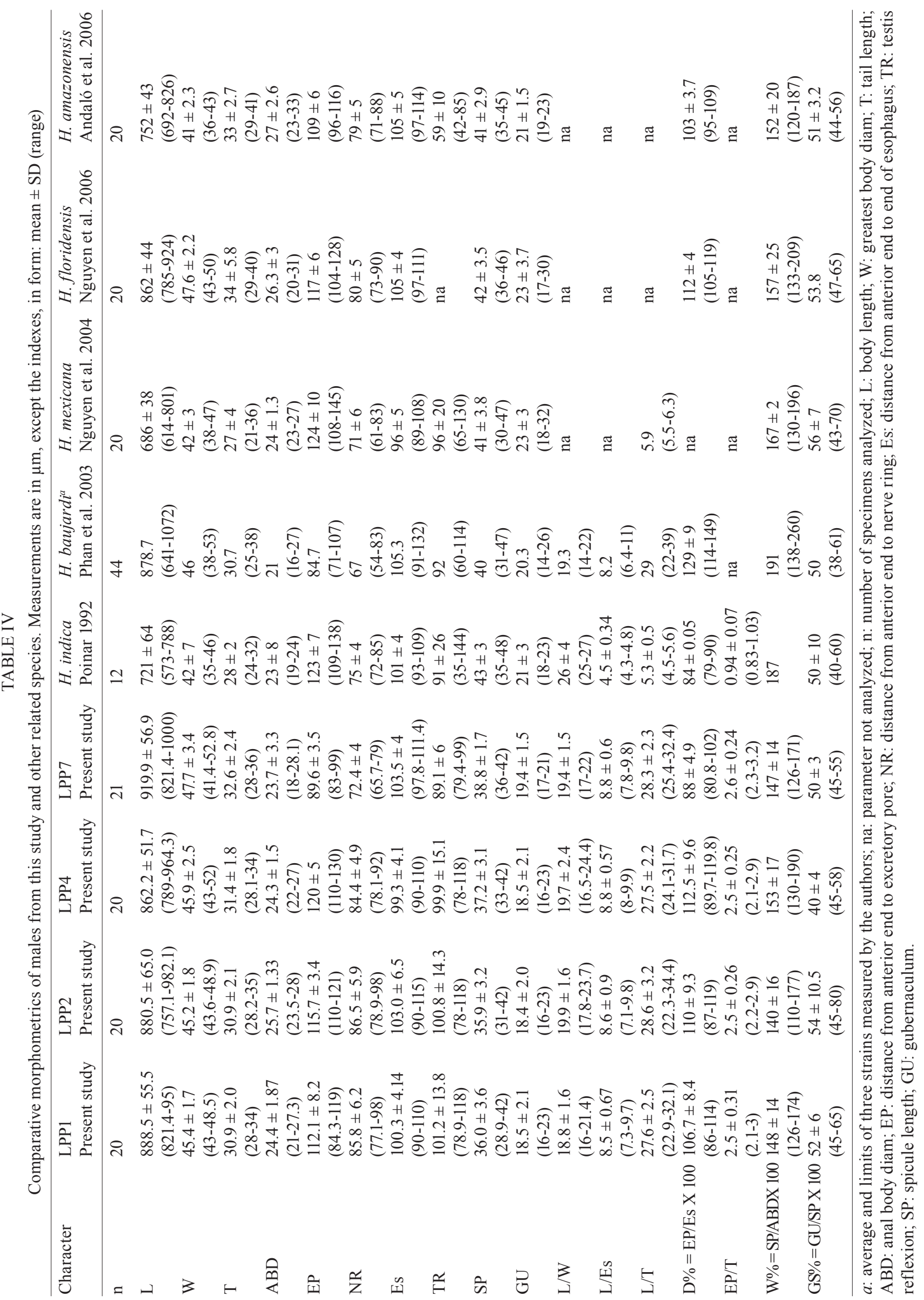


A

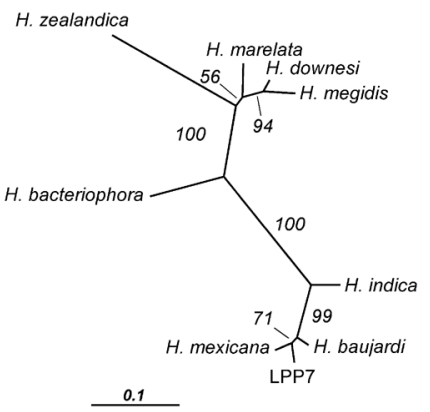

B

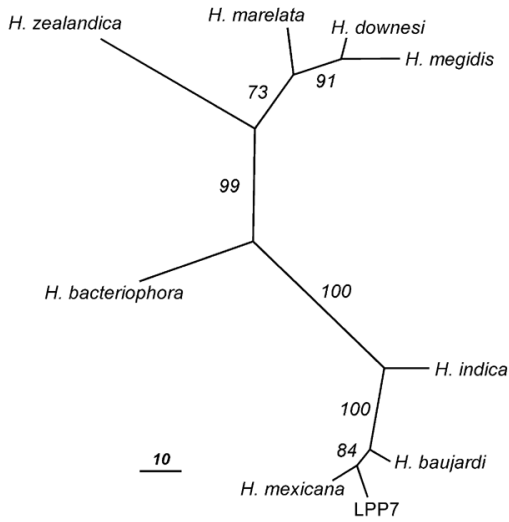

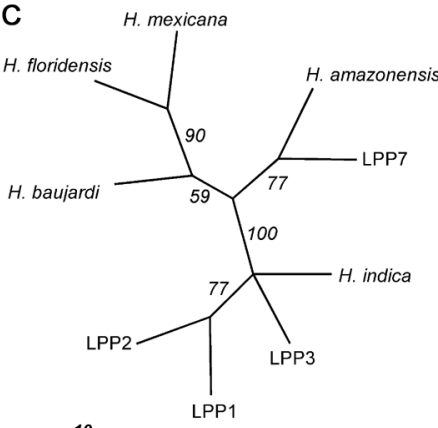

10

Fig. 6: phylogenetic analysis of Heterorhabditis species. A: maximum likelihood (ML) unrooted tree of ITS1 sequences, using a likelihood score of $1 \mathrm{nl}=1747.8$; B: maximum parsimony (MP) unrooted tree of ITS1 sequences, the best tree score found is 258 . From a total of 415 characters, 106 were parsimony-informative; C: ML unrooted tree of the "indica group" using ITS1 and ITS2 sequences. The scale bar is the number of substitutions per site. The bootstrap values are shown over the branches. Analyses were made as described in Materials and Methods. The scale bar shows the number of substitutions per site.

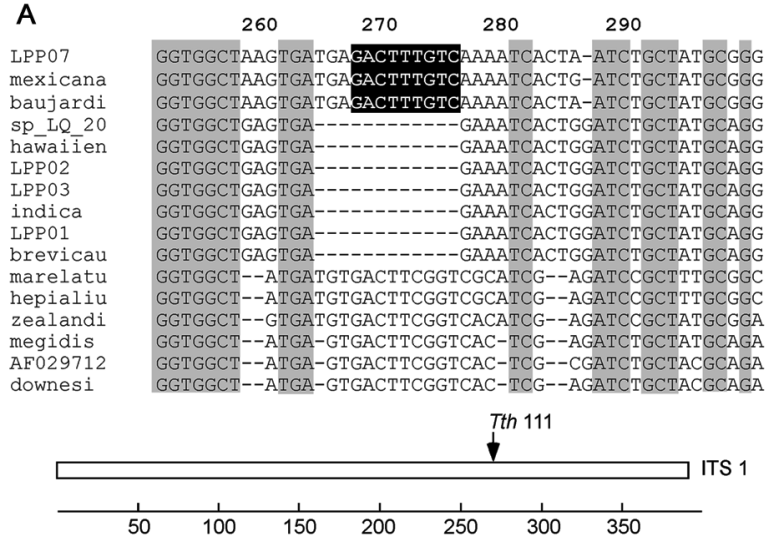

B

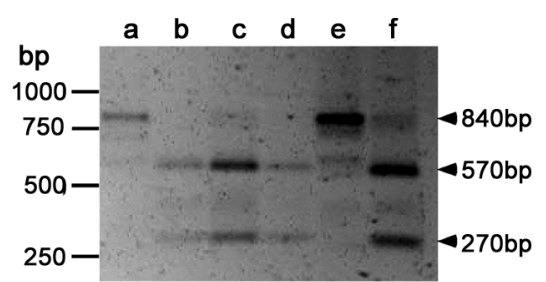

Fig. 7: restriction fragment length polymorphism (RFLP) analysis of ITS sequences. A: partial alignment of ITS1 sequences from Heterorhabditis spp. Gray boxes show unvariable positions. The black box show the restriction site for Tth 111 found only in the "baujardi subgroup". Below the alignment the scheme shows the relative position of Tth 111 site in the ITS1 sequence; B: RFLP analysis of ITS fragment obtained by polymerase chain reaction (PCR). The PCR fragments obtained from several samples were digested with Tth 111 and submited to agarose gel electrophoresis and Ethidium bromide staining; a: LPP4; b: LPP5; c: LPP7; d: LPP8; e: LPP9, and f: LPP10.

Further analysis of the ITS1 alignment indicated the presence of a unique sequence in the "baujardi subgroup" (LPP7, H. baujardi, H. mexicana, H. floridensis and H. amazonensis, Fig. 5). This unique sequence contains the cleavage site of the restriction enzyme $T t h$
111 (Fig. 7A). Digested ITS1-5S-ITS2 PCR fragments from unsequenced and sequenced LPP strains were used to diagnose to which group they belong (Fig. 7B). This analysis confirmed the sequence results and showed that the unsequenced isolates LPP5, LPP8 and LPP10 belong to the "baujardi sub-group", while LPP4 and LPP9 belong to the "indica sub-group". Therefore, based on ITS sequence and restriction fragment length polymorphism, the strains from the rainforest of Monte Negro, Rondônia, LPP1, LPP2, LPP3, LPP4 and LPP9 were considered to be H. indica whereas the strains LPP5, LPP7, LPP8 and LPP10 were considered to be H. baujardi.

Species delimitation can be difficult as discussed extensively by Adams (2001) and Sites and Marshall (2004). The accurate description of a new nematode species is an especially cumbersome task, due to the morphological and reproductive diversity of nematodes (Nadler 2002). Our data on the ITS sequences from Monte Negro isolates suggest the presence of two distinct groups of nematodes of the genus Heterorhabditis, which live in sympatry. Data presented in this paper do not allow us to delimit new species or review the already described species of Heterorhabditis found in tropical regions. In order to avoid taxonomic inflation (Isaac et al. 2004), these isolates should be considered as members of the previously well characterized species, $H$. baujardi and $H$. indica until more experimental data are obtained. The number of sequences we have for the "indica subgroup" isolates (LPP1, 2, 3) support their classification within the previously described species $H$. indica, as was done with H. hawaiiensis (Adams et al. 1998). The only "baujardi sub-group" sequence (LPP7) presented here, makes it difficult to decide if it belongs to the newly described $H$. amazonensis (Andaló et al. 2006) or to the $H$. baujardi isolated in the forests of Vietnam (around 10$14^{\circ} \mathrm{N}, 107^{\circ} \mathrm{E}$ ) (Phan et al. 2003). It is interesting that $H$. baujardi and $H$. indica were found in the same collecting areas of Vietnam (Phan et al. 2003), similar to what we found in the Amazonian forest $\left(10^{\circ} \mathrm{S}, 63^{\circ} \mathrm{W}\right)$, but not necessarily as sympatric populations. 
Considering the great geographical distances among sites of occurrence for the "indica sub-group" nematodes (i.e., Vietnam, India and Brazil), we envision two possible scenarios: the isolates belong to different species, based on their geographical origin, or they all belong to previously described species. Recently it was shown that gene sequence haplotypes of Caenorhabditis briggsae show very little diversity around the globe when considering the same latitude, but that they vary depending on distance to the equator and create what Dolgin et al. (2008) called "latitudinal clades". Thus, isolates of $H$. indica around the globe might also be "latitudinal clades", but more extensive studies are needed to test this hypothesis.

Our data on gubernaculum morphology successfully differentiated $H$. baujardi from $H$. indica, and we suggest that this character should be investigated more thoroughly in the other described species in this group (i.e., H. amazonensis, H. mexicana and H. floridensis) to better define their species status.

\section{ACKNOWLEDGEMENTS}

To Khuong Nguyen for sharing unpublished data. To Grace Kelly dos Santos for rearing G. mellonella larvae (TECNORTE fellowship). To UENF/LBCT for the light microscope facilities, Dr. Luís Marcelo de Aranha Camargo, and staff at ICB5/USP for help in collecting the samples.

\section{REFERENCES}

Adams BJ 2001. The species delimitation uncertainty principle. J Nematol 33: 153-160.

Adams BJ, Burnell AM, Powers TO 1998. A phylogenetic analysis of Heterorhabditis (Nemata: Rhabditidae) based on internal transcribed spacer 1 DNA sequence data. J Nematol 30: 22-39.

Adams BJ, Fodor A, Klein MG, Smith HL, Stackebrandt E, Stock SP 2006. Biodiversity and systematics of nematode-bacterium entomopathogens. Biol Control 37: 32-49.

Andaló V, Nguyen KB, Moino A 2006. Heterorhabditis amazonensis n.sp. (Rhabditida: Heterorhabditidae) from Amazonas, Brazil. Nematology 8: 853-867.

Bedding RA, Akhurst RJ 1975. A simple technique for the detection of insect parasitic rhabditid nematodes in soil. Nematologica 21: 109-110.

Blaxter ML, De Ley P, Garey JR, Liu LX, Scheldeman P, Vierstraete A, Vanfleteren JR, Mackey LY, Dorris M, Frisse LM, Vida JT, Thomas WK 1998. A molecular evolutionary framework for the phylum Nematoda. Nature 392: 71-75.

Dolgin ES, Félix MA, Cutter AD 2008. Hakuna Nematoda: genetic and phenotypic diversity in African isolates of Caenorhabditis elegans and C. briggsae. Heredity 100: 304-315.

Dutky SR, Thompson JV, Cantwell GE 1964. A technique for the mass propagation of the DD-136 nematode. J Insect Pathol 6: 417-422.

Fitch DH 2000. Evolution of "Rhabditidae" and the Male Tail. $J$ Nematol 32: 235-244.

Gardner SL, Stock SP, Kaya HH 1994. A New Species of Heterorhabditis from the Hawaiian Islands. J Parasitol 80: 100-106.

Hominick WH 2002. Biogeography. In R Gaugler, Entomopathogenic Nematology, CABI Publishing, New York, p. 115-143.

Hominick WM, Briscoe BR, Garcia Del-Pino F, Heng J, Hunt DJ, Kozodoy E, Mracek Z, Nguyen KB, Reid AP, Spiridonon S, Stock P,
Sturhan D, Waturu C, Yoshida M 1997. Biosystematics of entomopathogenic nematodes: current status, protocols and definitions. $J$ Helminthol 71: 271-298.

Hominick WM, Reid AP, Bohan DA, Briscoe BR 1996. Entomopathogenic nematodes: Biodiversity, geographical distribution and de convention on Biological Diversity. Biocontrol Sci Technol 6: 317-331.

Isaac NJB, Mallet J, Mace GM 2004. Taxonomic inflation: its influence on macroecology and conservation. Trends Ecol Evol 19: 464-469.

Josephrajkumar A, Sivakumar CV 1997. A survey for entomopathogenic nematodes in Kanyakumari district, Tamil Nadu, India. Indian J Entomol 59: 45-50.

Liu J 1994. A new species of the genus Heterorhabditis from China (Rhabditidae: Heterorhabditidae). Acta Zool Sinica 19: 268-272.

Mason JM, Razak AR, Wright DJ 1996. The recovery of entomopathogenic nematodes from selected areas within Peninsular Malaysia. J Helminthol 70: 303-307.

Nadler SA 2002. Species delimitation and nematode biodiversity: phylogenies rule. Nematology 4: 615-625.

Newton LA, Chilton NB, Beveridge I, Hoste H, Nansen P, Gasser RB 1998. Genetic markers for strongylid nematodes of livestock defined by PCR-based restriction analysis of spacer rDNA. Acta Trop 69: 1-15.

Nguyen KB, Shapiro-Ilan DI, Stuart RJ, McCoy CW, James RR, Adams BJ 2004. Heterorhabditis mexicana $\mathrm{n}$. sp. (Rhabditida: Heterorhabditidae) from Tamaulipas, Mexico, and morphological studies of the bursa of Heterorhabditis spp. Nematology 6: 231-244.

Nguyen KB, Smart Jr GC 1995. Morphometrics of infective juveniles of Steinernema spp. and Heterorhabditis bacteriophora (Nemata: Rhabditida. J Nematol 27: 206-212.

Phan LK, Subbotin SA, Nguyen CN, Moens M 2003. Heterorhabditis baujardi sp. $\mathrm{n}$. (Rhabditida: Heterorhabditidae) from Vietnam with morphometric data for $H$. indica populations. Nematology 5: $367-382$.

Poinar Jr GO 1976. Description and biology of a new insect parasitic rhabditoid, Heterorhabditis bacteriophora n. sp. (Rhabditida: Heterorhabditidae n. fam.) Nematologica 21: 463-470.

Poinar Jr GO, Jackson T, Klein M 1987. Heterorhabditis megidis sp. n. (Heterorhabditidae: Rhabditida) parasitic in the Japanese beetle, Popillia japonica (Scarabaeidae: Coleoptera), in Ohio. Proc Helminthol Soc Washington 54: 53-59.

Poinar Jr GO, Karunakar GK, David H 1992. Heterorhabditis indica n.sp. (Rabditida: Nematoda) from India: separation of Heterorhabditis spp. by infective juveniles. Fundam Appl Nematol 15: 467-472.

Posada D, Crandall KA 1998. Modeltest: Testing the model of DNA substitution. Bioinformatics 14: 817-818.

Rosa JS, Bonifassi E, Amaral J, Lacey LA, Simões N, Laumond C 2000. Natural Occurrence of Entomopathogenic Nematodes (Rhabditida: Steinernema, Heterorhabditis) in the Azores. J Nematol 32: 215-222.

Shamseldean MM, El-Sooud AB, Abd-Elgawad MM, Saleh MM 1996. Identification of a new heterorhabditid species from Egypt, Heterorhabditis taysearae, n. sp. (Rhabditida: Heterorhabditiade). Egypt J Bio Pest Control 6: 129-138.

Sites JW Jr, Marshall JC 2004. Operational criteria for delimiting species. Annu Rev Eco Evol Syst 35: 199-227.

Smits PH, Ehlers RU 1991. Identification of Heterorhabditis spp. by morphometric characters and RFLP and of their symbiotic bacteria Xenorhabdus spp. by species specific DNA probes. Bull SROP/WPRS 14: 195-201. 
Stock SP, Campbell JF, Nadler SA 2001. Phylogeny of Steinernema Travassos, 1927 (Cephalobina: Steinernematidae) inferred from ribosomal DNA sequences and morphological characters. J Parasitol 87: 877-889.

Stock SP, Kaya HK 1996. A multivariate analysis of morphometric characters of Heterorhabditis species (Nemata: Heterorhabditidae) and the role of morphometrics in the taxonomy of species of the genus. J Parasitol 82: 806-813.

Stock SP, Strong DR, Gardner SL 1996. Identification of Heterorhabditis (Nemata: Heterorhabditidae) from California with a new species isolated from the larvae of the ghost moth Hepialis californicus (Lepidoptera: Hepialidae) from the Bodega Bay Natural Preserve. Fundam Appl Nematol 19: 585-592.
Stuart RJ, Gaugler R 1994. Patchiness in populations of entomopathogenic nematodes. J Invertebr Pathol 64: 39-45.

Swofford DL 1998. PAUP*. Phylogenetic analysis using parsimony (* and other methods), version 4.0, Sinauer, Sunderland, MA.

Thompson JD, Gibson TJ, Plewniak F, Jeanmougin F, Higgins DG 1997. The ClustalX windows interface: flexible strategies for multiple sequence alignment aided by quality analysis tools. Nucleic Acids Res 24: 4876-4882.

White GF 1927. A method for obtaining infective nematode larvae from culture. Science 66: 302-303.

Wimmer B 2007. A compilation of primers - ITS Primer Sets. [updated 2006 Nov 20; cited 2008 Jan 17]. Available from: http:// www.nematodes.org/nematodes/npg/primersets.html 